\title{
Appendicization of the colon after appendectomy
}

\author{
Mithilesh Sinha ${ }^{1}$ and Upendra Hansda ${ }^{1}$ \\ ${ }^{1}$ AIIMS Bhubaneswar
}

January 2, 2022

\begin{abstract}
The blind colonic loop following end to side ileo- sigmoid anastomosis resembles a vermiform appendix in anatomy and function. This anatomical alteration is associated with delayed complications and is not advisable.
\end{abstract}

TITLE: Appendicization of the colon after appendectomy

\section{ABSTRACT}

The blind colonic loop following end to side ileo- sigmoid anastomosis resembles a vermiform appendix in anatomy and function. This anatomical alteration is associated with delayed complications and is not advisable.

Keywords: Blind loop syndrome; Colon; Colonic diverticula; Vermiform appendix.

\section{DESCRIPTION OF THE CASE}

A 75-year-old man presented to the surgical emergency with abdominal pain and constipation for three days. He underwent appendectomy 25 years back and had no other comorbidities. His abdomen was hugely distended, and there was a right paramedian scar on it. During the exploratory laparotomy, the ileum was found anastomosed with sigmoid colon. The vermiform appendix was missing at the base of the caecum. The blind tube of the colon proximal to ileo- sigmoid anastomosis was hugely distended and gangrenous. (Figure-1)

\section{DISCUSSION}

We could not find a term for the colonic blind tube following end to side ileo-sigmoid anastomosis. Calling it a 'giant diverticulum' may not be appropriate.[1] Phrases like 'blind loop of the colon' or 'defunctionalized loop of the colon' lack specificity.

We created 'Appendicization' by adding the suffix 'ization' to the word Appendix. [2] This surgical misadventure created an anatomy and clinical course similar to the vermiform appendix. The blind tube of the colon, just like a vermiform appendix, was seen arising from the confluence of ileum with colon. This pathological segment had an independent blood supply like an organ. It caused no harm to the host and then incidentally, after a long gap, got inflamed and developed gangrene.

Statement of Funding : We have not received any funding for this project.

Statement of Informed Consent: Written informed consent was obtained from the patient to publish this report in accordance with the journal's patient consent policy.

Conflict of interest: None

Author's contribution: 
Dr Mithilesh Kumar Sinha: Contributed to the concept, design, definition of intellectual content, literature search, data acquisition, manuscript preparation, manuscript editing and manuscript review.

Dr Upendra Hansda: Contributed to the concept, design, definition of intellectual content, literature search, manuscript editing and manuscript review.

REFERENCES

1. Diverticulum. In: The Free Dictionary [Internet]. [cited 2021 May 28]. Available from: https://medicaldictionary.thefreedictionary.com/diverticulum.

2. Ization Meaning | Best 3 Definitions of Ization [Internet]. [cited 2021 May 28]. Available from: https://www.yourdictionary.com/ization.

FIGURE CAPTIONS

Figure- 1: Resected specimen showing ascending colon beginning as a blind sac and without an appendix, the transverse colon and the descending colon. Gangrenous patches (Black arrow) and ileo-sigmoid anastomosis (Yellow arrow) are also seen. 


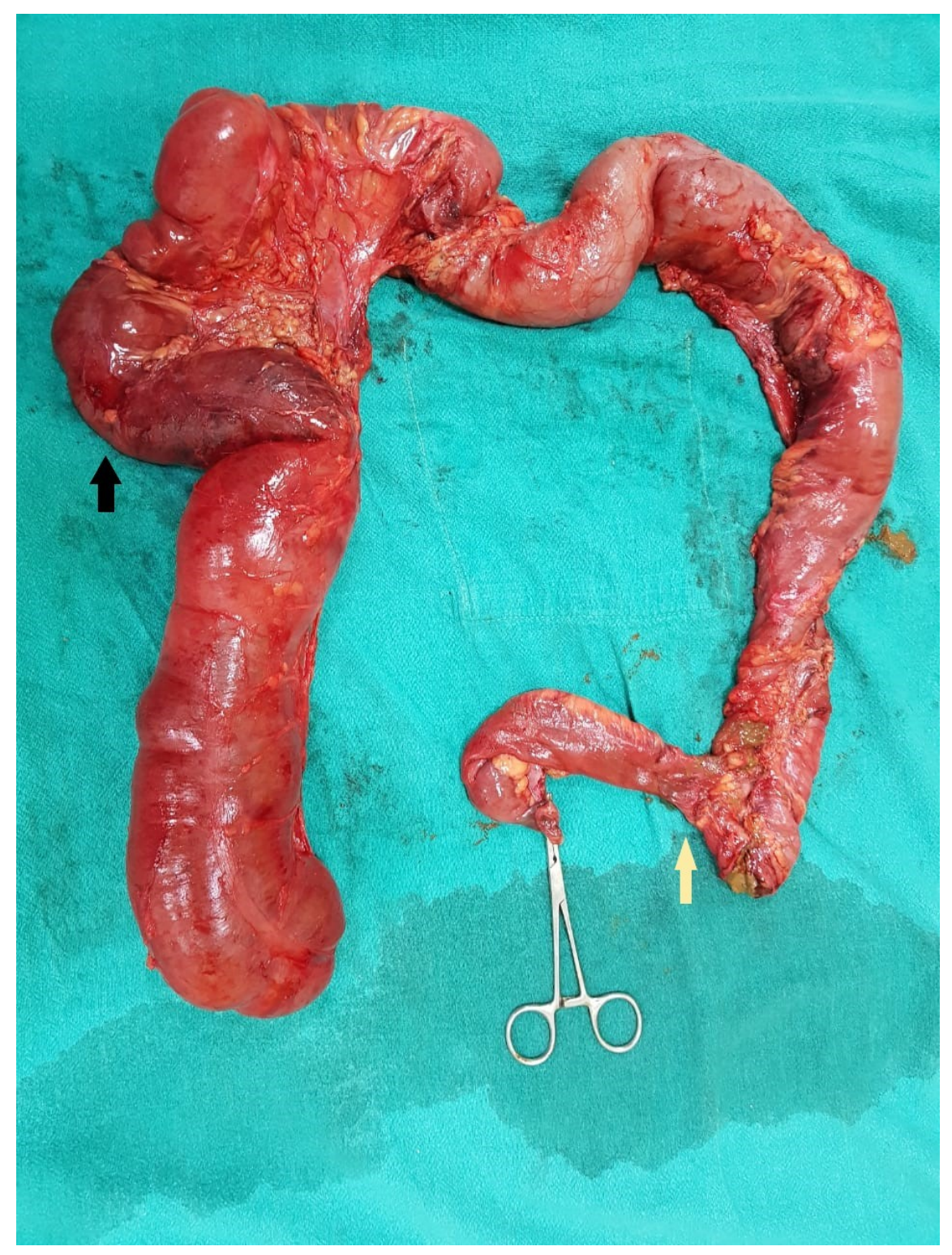

